ఠ

OPEN ACCESS

EDITADO POR

- Raquel Freitag (UFS)

AVALIADO POR

- Márcia Freitas (UNIFEI)

- Renato Pereira (UFMS)

SOBRE OS AUTORES

- Jean Michel Pimentel Rocha

Conceptualização, Curadoria

de Dados, Análise Formal,

Aquisição de Financiamento,

Investigação, Metodologia,

Recursos, Visualização, Escrita

- rascunho original -, Escrita -

análise e edição.

- Vander Viana

Curadoria de Dados, Análise

Formal, Metodologia, Recursos,

Supervisão, Visualização,

Escrita - rascunho original -,

Escrita - análise e edição.

- Adriane Orenha-Ottaiano

Investigação, Recursos,

Supervisão, Visualização,

Escrita - análise e edição.

DATAS

- Recebido: 03/10/2020

- Aceito: 03/11/2020

- Publicado: 16/11/2020

COMO CITAR

Rocha, J. M. P.; Viana, V.;

Orenha-Ottaiano, A. (2020)

Tradução de fraseologismos

metafóricos: contribuições

teórico-metodológicas da

linguística de corpus. Revista da Abralin, v. 19, n. 1, p. 1-26, 2020.

\title{
Tradução de fraseologismos metafóricos: contribuições teórico-metodológicas da linguística de corpus
}

\author{
Jean Michel Pimentel ROCHA (D) \\ Universidade Estadual Paulista (UNESP) \\ Vander VIANA (D) \\ Universidade de East Anglia (UEA) \\ Adriane ORENHA-OTTAIANO (D) \\ Universidade Estadual Paulista (UNESP)
}

\section{RESUMO}

O objetivo deste artigo é apresentar e discutir a contribuição teórico-metodológica da Linguística de Corpus para a análise de fraseologismos metafóricos traduzidos da língua portuguesa para a língua inglesa por estudantes universitários brasileiros. O artigo discorre, primeiramente, sobre as sinergias entre os estudos da metáfora, corpus e tradução, que têm possibilitado novos olhares para os estudos linguísticos. Posteriormente, é detalhada a proposta metodológica aqui sugerida, que é fundamentada na coocorrência estatística de unidades lexicais e em seus respectivos co-textos. A análise diferencia sequências lexicais de fraseologismos e usos metafóricos de nãometafóricos. Dessa forma, é possível identificar se as traduções propostas pelos universitários que participaram da pesquisa são ou não convencionais em língua inglesa. A título de exemplificação, o artigo apresenta e discute a análise de fraseologismos metafóricos que têm como metáforas conceituais subjacentes O CORPO É UM CONTÊINER, MEIOS SÃO CAMINHOS PARA UM PROPÓSITO, DESISTIR É ABANDONAR O BARCO e TERRORISMO É FENÔMENO DA NATUREZA. Os resultados apontam para a viabilidade da estratégia metodológica aqui proposta e apresentam suas inúmeras vantagens analíticas. 


\section{REVISTA DA ABRALIN}

\section{ABSTRACT}

This paper aims at presenting and discussing the theoretical and methodological contributions of Corpus Linguistics to the analysis of metaphorical phraseologies translated from Portuguese to English by Brazilian university students. The paper first discusses the synergies among metaphor, corpus and translation studies, which have afforded new vistas to linguistic studies. It then details the methodological proposal suggested here, which is based on the statistical co-occurrence of lexical units and their respective co-texts. The analysis differentiates lexical sequences from phraseologies and metaphorical uses from non-metaphorical ones. This way, it is possible to identify whether or not university students' proposed translations are conventional in the English language. For the sake of illustration, the paper presents and discusses the analyses of metaphorical phraseologies which have as underlying conceptual metaphors THE BODY IS A CONTAINER, MEANS ARE PATHS TO A PURPOSE, GIVING UP IS JUMPING FROM A SHIP and TERRORISM IS A NATURAL PHENOMENON. The results support the feasibility of the suggested methodological proposal and indicate its numerous analytical advantages.

\section{PALAVRAS-CHAVE}

Fraseologismo. Linguística de Corpus. Metáfora. Tradução. Corpus de Aprendizes.

\section{KEYWORDS}

Phraseologism. Corpus Linguistics. Metaphor. Translation. Learner Corpus.

\section{Introdução}

Ao longo das últimas décadas, a Linguística de Corpus (doravante LC) tem se consolidado cada vez mais dentro dos Estudos da Linguagem e tem contribuído para outras áreas do conhecimento. A versatilidade da LC pode ser explicada em parte porque ela pode ser empregada a partir de diferentes perspectivas epistemológicas (e.g. uma abordagem, uma metodologia, uma teoria) a depender do seu contexto de uso e dos objetivos de pesquisa (cf. VIANA; ZYNGIER; BARNBROOK, 2011). Um dos grandes diferenciais da LC está na aplicação de ferramentas computacionais para a observação, a descrição e a teorização do uso da língua sob o ângulo empírico (e.g. MCENERY; HARDIE, 2012; VIANA, 2011). Dessa forma, o foco da observação recai na língua em uso em oposição a abstrações ou 


\section{REVISTA DA ABRALIN}

conjecturas sobre esse uso; e o emprego de programas computacionais reduz, ao menos em um primeiro estágio, a possibilidade de uma análise enviesada por critérios subjetivos (e.g. BAKER, 2006).

Neste artigo, focamos em uma subárea específica na qual a LC tem tido grande influência ao longo dos anos: a Linguística Aplicada (e.g. HUNSTON, 2002; HYLAND; CHAU; HANDFORD, 2012). Mais especificamente, nos atemos ao emprego da LC na investigação da tradução do léxico metafórico por estudantes brasileiros de Tradução, com vistas a identificar a contribuição do aporte teórico-metodológico para os Estudos da Tradução e da Metáfora. De forma a consubstanciar os argumentos do presente artigo, contamos com os dados empíricos de Rocha (inédito), que objetiva analisar fraseologismos metafóricos traduzidos unidirecionalmente da língua portuguesa para a língua inglesa.

O presente artigo se divide em quatro seções. Na Seção 1, que sucede essa introdução, discorremos brevemente sobre a relação entre as três grandes áreas aqui envolvidas: os Estudos da Metáfora, a LC e a Tradução. A Seção 2 contém informações metodológicas: o corpus de estudo é descrito, e os procedimentos teórico-metodológicos advindos da LC relevantes à presente pesquisa são detalhados. Na Seção 3, a título de exemplificação do método empregado, examinamos os fraseologismos identificados nos dados em língua portuguesa que têm como metáforas conceituais subjacentes O CORPO É UM CONTÊINER, MEIOS S̃̃O CAMINHOS PARA UM PROPÓSITO, DESISTIR É ABANDONAR O BARCO E TERRORISMO É FENÔMENO DA NATUREZA. Por fim, na Seção 4, trazemos algumas considerações sobre o que indicam as primeiras análises e que vantagens podem ser observadas no método analítico proposto no presente artigo.

\section{Metáfora, corpora e tradução}

A versatilidade da LC (cf. Introdução) permite que ela seja empregada em diferentes disciplinas (BIBER; REPPEN, 2015; O'KEEFFE; MCCARTHY, 2010), revelando assim o seu potencial interdisciplinar. Nessa pesquisa, nos atemos à relação da LC com os Estudos da Metáfora e a Tradução. O nosso ponto de partida é a investigação do léxico metafórico. Por exemplo, apesar de "abandonar o barco" poder ser empregado literalmente em referência a alguém que tenha saído de uma embarcação náutica (e.g. "é necessário realizar um diagnóstico mais sistemático dos mecanismos de recrutamento e colocação dos trabalhadores marítimos em todo o mundo, incluídas as restrições ao direito de abandonar o barco que se aplicam na prática"²), estamos interessados no emprego de tal expressão com sentido metafórico, como no caso da não-manutenção de um apoio a um indivíduo ou instituição (e.g. "não foi por outra razão que Serra, até aqui, vinha apoiando Kassab contra Alckmin, apesar de ter abandonado o barco do prefeito, que já faz água por todos os lados"). A Tradução é igualmente

\footnotetext{
${ }^{1}$ Seguindo a literatura da área, empregamos a formatação versalete para indicação das metáforas conceituais.

${ }^{2}$ Ambos os exemplos fornecidos para "abandonar o barco" apresentados nessa frase foram retirados do corpus Portuguese Web 2011, que é empregado como corpus de referência em língua portuguesa (CRP) no presente estudo (cf. Seção 3).
} 


\section{REVISTA DA ABRALIN}

relevante para este estudo. A identificação do léxico metafórico em língua portuguesa é somente um primeiro estágio do presente estudo; o nosso principal foco analítico recai sobre a investigação das opções tradutórias dos fraseologismos metafóricos em português para a língua inglesa sugeridas por universitários brasileiros. Para continuar com o exemplo dado anteriormente, "abandonar o barco", a pergunta a ser respondida é como esses aprendizes traduzem esse fraseologismo para a língua inglesa - e.g. abandon/jump/leave a ship. Já a LC subjaz o nosso trabalho analítico tanto em relação à identificação inicial dos fraseologismos metafóricos em língua portuguesa quanto à análise das traduções para a língua inglesa propostas pelos participantes de pesquisa.

Para duas das áreas principais de nosso estudo, a LC e os Estudos da Metáfora, a década de 80 teve grande importância. Com a popularização dos computadores pessoais, a LC teve um crescimento exponencial: a análise empírica de dados de uso linguístico se tornou mais factível, acessível e confiável em comparação ao estágio anterior de análise manual (MCENERY; WILSON, 2001). Já nos Estudos da Metáfora, temos o surgimento da teoria da metáfora conceitual, lançada por Lakoff e Johnson (2003 [1980]). A teoria da metáfora conceitual, à época tão inovadora quanto à LC, veio para mostrar que a metáfora não é uma simples figura de linguagem restrita a uma função retórica, mas um fenômeno linguístico-cognitivo que contribui para a organização conceitual da realidade.

Segundo Lakoff e Johnson (2003 [1980]), a metáfora conceitual pode ser compreendida como a expressão de uma coisa em termos de outra. Trata-se de uma relação linguístico-cognitiva que envolve a chamada corporificação, isto é, como a organização motora do corpo, juntamente com as experiências físicas e socioculturais atuam na criação dos mapeamentos metafóricos (LAKOFF, 1987). Tais mapeamentos são constituídos por meio de correspondências entre domínios. Há um domínio fonte, cujas bases, em geral, são mais concretas, e um domínio alvo, de bases mais abstratas (KÖVECSES, 2010).

Na obra "Metáforas da vida cotidiana" (cf. LAKOFF; JOHNSON, 2003 [1980]), os pesquisadores exemplificam, a partir de variadas metáforas conceituais e de suas respectivas realizações linguísticas, como a ação humana no mundo tem bases metafóricas. Essa exemplificação pode ser trazida para o cenário da pandemia de coronavírus onde é possível identificar a metáfora conceitual COMBATER O CORONAVÍRUS É LUTAR EM UMA GUERRA, a partir de uma sentença como em "o que está acontecendo é uma guerra, ele reiterou. O inimigo é invisível, feroz, dedicado" ${ }^{3}$. Nesse caso, observa-se linguisticamente que elementos de uma guerra ou conflito são entendidos em um campo mais abstrato que não envolve uma luta física em um campo de batalha. Esse campo mais abstrato pode ser, por exemplo, o político, quando se trata das medidas de prevenção do avanço do vírus; ou o científico, quando se fala no desenvolvimento de uma vacina para combatê-lo.

Dado o foco no pensamento da teoria da metáfora conceitual, uma crítica inicialmente dirigida a ela se relacionava ao tratamento das evidências linguísticas. Desaprovava-se o fato de os exemplos utilizados serem, em geral, frutos de experiências introspectivas, podendo não refletir, verdadeiramente, o observado no uso de uma determinada língua. Essa avaliação negativa tem um paralelo com

${ }^{3}$ Excerto disponível em: https://noticias.uol.com.br/colunas/josias-de-souza/2020/03/18/cupula-da-republica-esta-cercadapelo-coronavirus.htm. Acesso em: 23 de julho de 2020. 


\section{REVISTA DA ABRALIN}

uma crítica também enfrentada pela LC, especialmente no período anterior à popularização dos computadores, quando dúvidas eram levantadas a respeito da confiabilidade da análise manual de dados empíricos (cf. VIANA; ZYNGIER, 2009).

Nos Estudos da Metáfora, Vereza (2013) argumenta que tal crítica carece de ponderação uma vez que exemplos advindos de atividade instrospectiva não necessariamente inexistem em uma língua. Em outras palavras, esses exemplos podem ser construções aceitas e utilizadas por uma comunidade linguística e sociocultural de que determinado falante é parte.

Apesar de concordarmos que a introspecção não seja em si um problema, não temos como deixar de notar as suas limitações: o repertório lexical de um falante e o seu conhecimento linguístico de forma geral são insuficientes para dar conta dos numerosos modos de dizer de uma língua e de suas variedades. Assim sendo, a análise de corpora se revela como uma forma de contornar essas restrições. Por mais que corpora não contenham todos os exemplos de uso de uma determinada língua, o que seria humanamente impossivel, essas criteriosas coletâneas textuais têm como objetivo serem amostras representativas de uma língua ou de seus usos específicos (BERBER SARDINHA, 2004; VIANA, 2011; VIANA; ZYNGIER; BARNBROOK, 2011). Dessa forma, a exploração de corpora tem um potencial muito maior do que a análise linguística baseada na introspecção de um ou de alguns falantes. O emprego de corpora pode facilitar a identificação e a observação de metáforas linguísticas, ampliando assim as possibilidades de análise de evidências empíricas, privilegiando a autenticidade e exploração da metáfora em diferentes gêneros textuais (BERBER SARDINHA, 2007; DEIGNAN, 2005; VEREZA, 2013).

A interface entre a LC e os Estudos da Metáfora é o ponto central em Deignan (1997). Seu trabalho precursor, fundamentado em uma abordagem baseada em corpus, expandiu os horizontes da pesquisa em metáfora, demonstrando como padrões colocacionais, sintáticos e semânticos auxiliam na constituição de mapeamentos conceituais. A aliança entre essas duas áreas do conhecimento tem-se mostrado frutífera resultando no desenvolvimento de métodos para identificação de metáforas em corpora (e.g. BERBER SARDINHA, 2011).

A interface corpus e metáfora marca a virada cognitivo-discursiva nos estudos metafóricos (VEREZA, 2010; 2013). Observa-se que, a partir da LC, houve uma reavaliação do papel da língua na investigação metafórica, em que o dado empírico passa a ter mais relevância, mesmo que continuasse sendo empregado para fins de verificação de hipóteses cognitivas. Vereza (2013) explica, ainda, que houve uma segunda virada discursiva, que foi além da exploração do dado autêntico e assinalou uma mudança de direção investigativa, favorecendo as teorizações sobre a metáfora no discurso. Nas palavras da autora, "o lócus da metáfora passa ser o discurso, se entendermos esse conceito como o espaço em que aspectos sociocognitivos e linguísticos [...] se encontram para tecer a figuratividade, entre outras formas de criação de sentidos" (VEREZA, 2010, p. 208). É no seio da perspectiva discursiva que surge o Procedimento de Identificação de Metáforas (PIM), discutido mais adiante, na Seção 2, empregado para seleção dos fraseologismos metafóricos em língua portuguesa no presente estudo. Trata-se de um método que também conta com auxílio de corpora em sua aplicação (cf. GRUPO PRAGGLEJAZ, 2007; STEEN, 2007). Essa breve revisão do histórico interdisciplinar da LC e dos Estudos da Metáfora sugere uma parceria que tem se consolidado ao longo dos anos. Observa-se, em 


\section{REVISTA DA ABRALIN}

maior ou menor grau, a participação da LC no redirecionamento dos caminhos e das decisões teórico-metodológicas nos estudos de metáforas.

Além dos Estudos da Metáfora e da LC, recorremos também aos Estudos da Tradução. A relação entre a Tradução e a LC é historicamente mais profícua do que àquela dos Estudos da Metáfora com a LC. As pesquisas de Baker $(1993 ; 1995)$ têm papel primordial na proposta e consolidação das investigações de tradução por meio de corpora, identificando e descrevendo padrões característicos no texto traduzido. Também alicerçada em corpus, Mauranen (2000; 2008) empenha-se em explorar e refletir sobre outros aspectos que influem no processo tradutório, como, por exemplo, interferência da língua de partida, sub ou sobreutilização de elementos da língua de chegada, além de emprego de coocorrências lexicais não convencionais.

No contexto brasileiro, a relação entre os Estudo da Tradução e a LC foi objeto de enfoque de "Corpora na tradução" (VIANA; TAGNIN, 2015), uma publicação inovadora ao ilustrar as diversas possibilidades analíticas que podem auxiliar a compreensão de questões tradutórias baseadas em corpora. Em "Linguística de corpus: Perspectivas" (FINATTO et al., 2018), há vários trabalhos que reforçam a parceria sólida entre essas duas áreas. Por exemplo, Rocha e Orenha-Ottaiano (2018), amparados pela LC, retomam um estudo (ROCHA, 2017) que objetivou a compilação de uma proposta de glossário trilíngue de colocações especializadas na área do direito comercial internacional. A referida proposta, elaborada nas direções tradutórias inglês $\rightarrow$ espanhol e espanhol $\rightarrow$ português, além de trazer contribuições metodológicas para as áreas da tradução e da LC, também teve como propósito um produto fraseográfico para atender as necessidades de tradutores profissionais, aprendizes de tradução, além de leigos e profissionais atuantes na área do direito.

A observação de características lexicogramaticais e semânticas através da análise de corpora contribui para a avaliação de uma hipótese mobilizada na presente pesquisa: a hipótese da tradução cognitiva (MANDELBLIT, 1995). Segundo essa hipótese, dificuldades na tradução poderiam ser motivadas por diferenças entre sistemas conceituais. Sendo os sistemas conceituais distintos (condição de mapeamento diferente - CMD), aprendizes teriam maior dificuldade em propor uma tradução convencional. Por outro lado, frente a similaridades entre sistemas conceituas (condição de mapeamento similar - CMS), a tradução poderia ser menos complexa. Como explicitaremos na Seção 3.2, no caso do fraseologismo metafórico "dar passos"/take steps, há uma CMS entre as línguas portuguesa e inglesa se considerarmos que, em ambas, a metáfora conceitual subjacente é MEIOS SÃO CAMINHOS PARA UM PROPÓSITO. No entanto, quando take measures é empregado como solução tradutória para "dar passos", há uma CMD. Nesse caso, coloca-se em evidência o domínio fonte grandeza física em vez do domínio fonte movimento/direção. Analisando as escolhas lexicais dos aprendizes e contrastando-as com o observado nas linhas de concordância, encontramos pistas semântico-cognitivas para fazer aproximações e apontar diferenças quanto às condições de mapeamento dos fraseologismos metafóricos nas línguas sob enfoque.

Neste trabalho, portanto, recorremos aos desenvolvimentos advindos das interfaces entre metáfora e corpora assim como tradução e corpora. É com o auxílio de corpora, em procedimento detalhado na próxima seção, que examinamos a convencionalidade dos fraseologismos metafóricos nos 


\section{REVISTA DA ABRALIN}

textos fonte em português e nas traduções propostas pelos participantes desta pesquisa. A LC mostra-se, assim, fundamental para verificar a idiossincrasia ou comunalidade das traduções sugeridas pelos participantes.

\section{Explorando a tradução de fraseologismos metafóricos por meio da LC}

A dificuldade de se trabalhar com fraseologismos pode ser observada logo em relação a sua nomenclatura. Há uma ampla gama de termos utilizados para se referir a eles tais como pacotes lexicais (DUTRA; BERBER SARDINHA, 2015) ou feixes lexicais (SHEPHERD; ZYNGIER; VIANA, 2006), unidades fraseológicas (CORPAS PASTOR, 1996), expressões convencionais (TAGNIN, 2013), entre outras. Essa diversidade de termos não é exclusiva da literatura em língua portuguesa: muitas das vezes, ela reflete a produção acadêmica em língua inglesa na qual tal variedade terminológica também foi identificada (cf. WRAY, 2002). Nem sempre os termos diferentes apontam para conceptualizações claramente distintas, o que dificulta ainda mais o trabalho nessa área.

O desafio da análise fraseológica não se restringe apenas à variação terminológica e conceitual. Nota-se também grande variedade no procedimento empregado para a identificação de fraseologismos tais como o emprego de obras literárias (TRISTÁ, 1988) ou dicionários (e.g. CARNEADO MORÉ, 1985; ORTÍZ ALVAREZ, 2000) como fonte de dados. Outras investigações, ainda que recorram à web como corpus, também têm no dicionário o principal ponto de partida para extração de fraseologismos (e.g. BARBOSA, 2014; FONSECA, 2013; VALENÇA, 2016).

Neste trabalho, a dificuldade se revela ainda maior uma vez que o nosso interesse recai em fraseologismos metafóricos. Assim sendo, a presente análise conjuga dois conceitos que não são de fácil operacionalização na prática. No tocante à análise metafórica, o desafio advém do emprego de certo trabalho manual e julgamento subjetivo, apesar da existência de propostas de abordagens semiautomáticas para a sua identificação (e.g. BERBER SARDINHA, 2011; DEIGNAN, 2005).

No tocante à questão terminológica, optamos por empregar "fraseologismos". Apesar de reconhecermos que esse termo possa ser visto como uma formulação genérica, ele atende ao propósito de nossa pesquisa. Ele evita o surgimento de debates desnecessários sobre a caracterização de sequências lexicais como, por exemplo, "tocar fundo". Não é relevante para os nossos propósitos se "tocar fundo" é uma colocação ou expressão idiomática. O aspecto que nos interessa é o fato de tal sequência se configurar em um fraseologismo e ser empregada de forma metafórica.

Para realizar a diferenciação entre meras sequências lexicais e fraseologismos, conjugamos a abordagem fraseológica tradicional (CORPAS PASTOR, 1996; ZULUAGA, 1980; RUIZ GURILO, 1997), que destaca aspectos linguísticos na formação dos fraseologismos, e a abordagem de frequência 


\section{REVISTA DA ABRALIN}

(EVERT, 2005; NESSELHAUF, 2005; GRANGER; PAQUOT, 2008), que destaca a força associativa de uma combinatória. Nossa compreensão de fraseologismo envolve três características principais.

a) Pluriverbalidade: trata-se de uma combinação com duas ou mais palavras formalmente estruturada em um sintagma.

b) Semântica marcada por (relativa) composicionalidade/idiomaticidade: o sentido da sequência lexical pode ser (mais ou menos) opaco/não composicional ou (mais ou menos) transparente.

c) Associabilidade: os constituintes do fraseologismo precisam ter uma força associativa estatisticamente relevante, não sendo apenas uma coocorrência aleatória, mas uma coocorrência institucionalizada no dizer coletivo.

Essas três características guiaram o levantamento dos fraseologismos em língua portuguesa. Vale ressaltar que esses traços nem sempre são discretos e podem gerar certa dificuldade analítica, especialmente quando são projetados nas traduções de aprendizes.

Além da identificação de fraseologismos, também nos debruçamos na questão metafórica. Em outras palavras, fizemos a diferenciação entre fraseologismo não-metafórico como "carta de baralho" (no sentido de carta de um jogo) em oposição a um fraseologismo metafórico como "carta na manga" (no sentido de uma estratégia/recurso para evitar algo ou uma situação). Não optamos, no entanto, por uma correspondência única entre fraseologismos e metáfora, porque entendemos que a metaforicidade é construída e observada em contextos de uso específicos. Assim sendo, "carta de baralho" não é metafórico em "ao invés de jogos infantis no jardim, com as outras crianças, preferia construir, sozinho, complicadas estruturas com cubos de madeira e grandes castelos de cartas de baralho, alguns com catorze andares", mas "carta fora do baralho" como empregado em "o presidente licenciado do Senado, Renan Calheiros (PMDB/AL), já é carta fora do baralho" se revela metafórico. Por esse motivo, nossa análise metafórica é calcada no estudo de linhas de concordância, como explicado a seguir.

Nosso corpus de estudo ${ }^{5}$ integra o projeto Multilingual Student Translation, também conhecido pelo acrônimo MUST (GRANGER; LEFER, 2018). Esse projeto visa a coleta de traduções feitas por tradutores aprendizes e aprendizes de língua. Envolve diferentes línguas e direções tradutórias, e diferentes gêneros textuais. Os corpora compilados se integram à plataforma Hypal ${ }^{6}$, cujas

\footnotetext{
${ }^{4}$ Exemplos também retirados do corpus de referência em português (CRP - cf. Seção 3).

${ }^{5}$ Este corpus obteve aprovação no Comitê de Ética em Pesquisa do IBILCE/UNESP, em 01/04/2019, CAAE nº 94053718.4.0000.5466, denominado Corpus de Aprendizes de Tradução (CAT) e Multilingual Student Translation Corpus - MUST.

${ }^{6}$ Hypal. Disponível em: https://hypal.eu/hypal/. Acesso em: 25 de julho de 2020.
} 


\section{REVISTA DA ABRALIN}

funcionalidades envolvem alinhamento automático e semiautomático de textos traduzidos, bem como etiquetagem de textos em corpora de aprendizes e corpora de tradução.

O corpus deste estudo, coletado sob coordenação da Profa. Adriane Orenha-Ottaiano, é um corpus paralelo na direção tradutória português $\rightarrow$ inglês. Seu ponto de partida é um conjunto de 20 textos jornalísticos em língua portuguesa (entre 500 e 800 palavras) sobre temas educacionais e políticos para citar apenas dois exemplos. Esses textos, que totalizam 13.520 palavras, foram traduzidos para o inglês por 21 alunos universitários dos cursos de Bacharelado em Tradução e Licenciatura em Letras de uma universidade pública brasileira, com nível de proficiência variando de intermediário a avançado (B1-C1 no Quadro Europeu Comum de Referência para Línguas). Foram feitas 302 traduções, resultando em corpus em língua inglesa com 205.176 palavras.

Nos textos em português, o levantamento dos fraseologismos metafóricos teve como ponto de partida a análise metafórica. Devido ao reduzido tamanho dos textos em português, essa análise foi realizada de forma manual, tendo-se como parâmetro norteador o Procedimento de Identificação de Metáforas (PIM), idealizado pelo Grupo Pragglejaz (2007). Há uma série de passos definidos pelo grupo para identificar a metáfora linguística; porém, em termos gerais, o grupo concebe vocábulos ou multipalavras como metafóricas contrastando significados básicos e contextuais. Se o significado contextual contrasta com o básico, podendo ser entendido em relação a ele a partir de possíveis correlações semânticas, a unidade sob análise é considerada metafórica. Novamente, tomemos como exemplo o fraseologismo "abandonar o barco", retirado de um dos textos fonte (TF) em português:

(1) Discreto organizador nos bastidores, o presidente soube abandonar o barco de Dilma Rousseff a tempo, reclamando de ser um "vice-presidente decorativo". (TF)

Neste caso, não se trata de abandonar uma embarcação, em seu sentido concreto, mas de desistir ou deixar de apoiar uma situação ou alguém, no sentido contextual. Para usar uma expressão náutica, é como se alguém, ao abandonar uma instituição (ou o barco), a deixasse à deriva, sem apoio ou sem rumo. Ressaltamos que, para além dos corpora de referência, para analisar a metaforicidade, especialmente para contrastar significados básicos e contextuais, em língua portuguesa, contamos com o auxílio do dicionário Houaiss (2009). Na língua inglesa, recorremos aos dicionários on-line Cambridge (2020) e Macmillan (2020).

Apesar de a identificação de metaforicidade ter se dado por meio da análise manual dos dados, estabelecemos dois critérios menos subjetivos para a decisão final a respeito da inclusão ou exclusão de dados.

a) O uso da sequência tinha que ser predominantemente metafórico nas linhas de concordância examinadas tanto em português quanto em inglês.

b) No caso da língua inglesa, as traduções propostas pelos aprendizes tinham que apresentar compatibilidade semântica com a sequência lexical em português, a língua fonte. 


\section{REVISTA DA ABRALIN}

Em outras palavras, não poderia haver incongruência ou contradição semântica. A sugestão tradutória play deeper, por exemplo, é incompatível semanticamente em relação à "tocar fundo" (cf. Seção 3.1). Deeply touched, por sua vez, recupera o mesmo sentido veiculado no fraseologismo do TF, sendo com ele compatível.

Esses critérios pautaram a nossa análise de uma amostra de 100 linhas de concordância selecionadas aleatoriamente pela ferramenta Sketch Engine nos corpora de referência em português e em inglês. A análise foi naturalmente realizada para cada sequência lexical identificada manualmente nos textos fonte em português e proposta nas traduções em inglês pelos participantes da pesquisa.

A título de ilustração, apresentamos a sequência lexical "capitão de time". Em um dos textos em língua portuguesa utilizados na pesquisa, o fraseologismo aparece no seguinte contexto:

(2) Dirceu tem agido nas sombras. Mal completou dois meses de liberdade e o ex-capitão do time de Lula parece ter readquirido ritmo de jogo.

Uma vez que o seu uso nesse texto fonte é claramente metafórico, a sequência foi inicialmente selecionada como possível fraseologismo metafórico. No entanto, ao analisar as linhas de concordância no corpus de referência Portuguese Web 2011 (ptTenTen - variedade brasileira), disponível no Sketch Engine (KILGARRIFF et al., 2014), observamos que o sentido metafórico aparece em apenas quatro, das 100 ocorrências aleatoriamente selecionadas. As demais referem-se ao sentido básico, ou seja, a de uma função de liderança de um jogador em um time de futebol. Essa talvez seja uma metáfora não tão comum, possivelmente proveniente de um momento enunciativo particular, e ainda não institucionalizada. Não incluímos essa sequência lexical em nossa análise visto que o objetivo era privilegiar fraseologismos predominantemente metafóricos.

Ao todo, foram levantadas cerca de 200 sequências lexicais candidatas a fraseologismos metafóricos. A segunda parte da análise contempla a questão fraseológica. Inicialmente, investigou-se no corpus de referência em português se as sequências lexicais manualmente levantadas nos textos jornalísticos que serviram de base para o presente estudo atendiam à característica fraseológica de associabilidade. Para tanto, foram aplicados os testes estatísticos escore T, informação mútua e LogDice. O escore T indica o grau de confiança que podemos ter da existência de uma combinação entre as palavras investigadas. A informação mútua e o LogDice, por sua vez, indicam a exclusividade da combinação em relação às frequências isoladas de suas unidades constituintes.

Para que uma sequência lexical fosse considerada um fraseologismo, foram estabelecidos critérios de corte para cada um dos testes. Com base na literatura da área (cf. BERBER SARDINHA, 2011; BREZINA; MCENERY; WATTAM, 2015; DURRANT; SCHMITT, 2009; FRANKENBERG-GARCIA, 2018; STUBBS, 2001), adotamos como valores mínimos dois para o escore T, e três para informação mútua e LogDice. Baseando-nos em Berber Sardinha (2011), estabelecemos que, para ser identificada como fraseologismo, uma sequência lexical deveria atender no mínimo dois dos valores de corte 


\section{REVISTA DA ABRALIN}

estipulados. Assim sendo, desconsideramos as sequências levantadas em português que não passaram nos testes como exemplificado na Tabela 1.

\begin{tabular}{|l|l|l|c|c|c|c|c|}
\hline \multicolumn{1}{|c|}{ Fraseologismo } & Nódulo & Colocado & Posição & $\begin{array}{c}\text { Freq. Nódulo e } \\
\text { colocado }\end{array}$ & Escore T & Informação mútua & LogDice \\
\hline abrir uma crise & crise & abrir & 2E & 329 & 12,79 & 2,92 \\
\hline $\begin{array}{l}\text { comprar o si- } \\
\text { lêncio }\end{array}$ & silêncio & comprar & 2E & 101 & 7,92 & 2,24 \\
\hline $\begin{array}{l}\text { entrar em dí- } \\
\text { vida }\end{array}$ & dívida & entrar & $2 \mathrm{E}$ & 104 & 2,69 & 0,44 \\
\hline $\begin{array}{l}\text { defender a flo- } \\
\text { resta }\end{array}$ & floresta & defender & 2E & 227 & 12,90 & 2,70 \\
\hline $\begin{array}{l}\text { estar na lan- } \\
\text { terna }\end{array}$ & lanterna & estar & 2E & 482 & 15,92 & 1,90 \\
\hline perder a trilha & trilha & perder & 2E & 107 & 6,40 & 2,95 \\
\hline
\end{tabular}

TABELA 1 - Força de associação entre nódulo e colocado

Fonte: os autores

Os exemplos apresentados na Tabela 1 contemplam sequências lexicais que passaram apenas no teste escore T. Isso indica que não são combinações aleatórias, isto é, as palavras parecem coocorrer de forma estatisticamente consistente. Contudo, as sequências não passaram nos testes informação mútua ou LogDice, que demonstram a força da associação das palavras.

O emprego do ponto de corte com base em dois testes estatísticos serve primeiramente ao propósito de identificar fraseologismos propriamente ditos nas línguas portuguesa e inglesa. Além disso, essa decisão também contribuiu metodologicamente para delimitar o número de dados para análise, tornando-a temporalmente factível. Dessa forma, a inclusão ou exclusão de dados na análise não se dá por uma decisão exclusivamente subjetiva dos pesquisadores. A adoção de um ponto de corte estatístico reduz a possibilidade de enviesamento dos dados selecionados (cf. BAKER, 2006) e permite a replicação do estudo por outros pesquisadores.

Após a identificação das sequências que atenderam tanto à análise metafórica quanto à fraseológica, chegamos a um total de 81 fraseologismos metafóricos nos textos fonte em língua portuguesa. Esses foram utilizados como ponto de partida para a análise comparativa entre as línguas portuguesa e inglesa por meio das traduções propostas pelos participantes da pesquisa.

O método seguido em língua inglesa é similar ao adotado em língua portuguesa com a identificação em duas etapas - fraseológica e metafórica. Há duas diferenças metodológicas, no entanto. A primeira se refere à ordem das etapas: em língua inglesa, a análise fraseológica precedeu a metafórica. Isso se deve ao fato de a primeira ser mais facilmente realizada com o auxílio computacional (i.e. a realização dos testes estatísticos para a diferenciação entre uma sequência lexical e um fraseologismo). A outra diferença metodológica se relaciona à escolha do corpus de referência. Naturalmente, optamos por um corpus em língua inglesa e privilegiamos um que fosse comparável ao corpus de referência em português. Empregamos o English Web 2015 - enTenTen, que, assim como o Portuguese Web 2011 (ptTenTen), são da família (TenTen). Ambos os corpora foram compilados via web e organizados pelos mesmos critérios (KILGARRIFF et al., 2014). 


\section{REVISTA DA ABRALIN}

A última parte da metodologia aqui proposta contempla a classificação dos dados da pesquisa em três categorias, conforme explicitado a seguir.

a) FraMConv (Fraseologismo Metafórico Convencional): fraseologismos que atingem o limiar estatístico em ao menos dois dos testes estatísticos empregados (escore $\mathrm{T}>2$, informação mútua $>3$ e LogDice > 3), e que tenham, na amostragem das linhas de concordância do corpus de referência em língua inglesa, prevalência de usos metafóricos semanticamente compatíveis com o fraseologismo selecionado em língua portuguesa.

b) FraMPConv (Fraseologismo Metafórico Pouco Convencional): (i) fraseologismos que atingem o limiar estatístico em ao menos dois dos testes estatísticos empregados (escore $\mathrm{T}>2$, informação mútua $>3$ e LogDice $>3$ ) mas cujas ocorrências de uso contemplem predominantemente significados básicos/concretos; ou (ii) sequências lexicais que não atingem o limiar estatístico mas que apresentam padrões metafóricos semanticamente compatíveis com o fraseologismo selecionado em língua portuguesa.

c) FraMNConv (Fraseologismo Metafórico Não Convencional): fraseologismos ou sequências lexicais com incompatibilidade semântica com o fraseologismo do texto em língua portuguesa.

Cabe ressaltar que, em (a), o termo "convencional" se refere tanto ao fraseologismo quanto à sua metaforicidade. Em (b), o termo "pouco convencional" abarca ou a questão fraseológica (i.e. sequências lexicais que não atendem aos critérios estatísticos) ou a questão metafórica (i.e. fraseologismos que são predominantemente empregados em um sentido literal). Em (c), o termo "não convencional" se refere à uma incongruência semântica. Em outras palavras, apesar de ser metafórica, a proposta de tradução em língua inglesa não transmite ideia igual ou similar do fraseologismo selecionado em língua portuguesa.

Após essa descrição metodológica, a próxima seção será dedicada à análise de alguns fraseologismos metafóricos, apresentados em conformidade às metáforas conceituais que lhes subjazem.

\section{Análise e discussão dos dados}

Nesta seção, analisamos e discutimos alguns fraseologismos nos dados de pesquisa de forma a ilustrar a viabilidade de aplicação dos métodos explicados na Seção 2. Os fraseologismos são agrupados em relação às metáforas conceituais subjacentes: O CORPO É UM CONTÊINER (Seção 3.1), MEIOS SÃO CAMINHOS PARA UM PROPÓSITO (Seção 3.2), DESISTIR É ABANDONAR O BARCO (Seção 3.3) e TERRORISMO É FENÔMENO 


\section{REVISTA DA ABRALIN}

DA NATUREZA (Seção 3.4). Empregaremos os seguintes códigos para indicar a origem dos exemplos apresentados:

- $\quad$ TF: texto fonte, ou seja, um dos 20 textos jornalísticos escritos em língua portuguesa inicialmente selecionados para a pesquisa;

- $\quad$ CEI: corpus de estudo em inglês, que contempla as traduções dos TFs para a língua inglesa realizadas pelos participantes da pesquisa;

- CRP: corpus de referência em português adotado na presente pesquisa - i.e. Portuguese Web 2011 (ptTenTen - variedade brasileira);

- CRI: corpus de referência em inglês comparável ao CRP - i.e. English Web 2015 - enTenTen.

\subsection{O CORPO É UM CONTÊINER}

A metáfora conceitual o CORPO É UM CONTÊINER (LAKOFF, JOHNSON, 2003 [1980]) se faz presente no TF representada pelo fraseologismo metafórico "tocar fundo".

No exemplo a seguir, "tocar fundo" relaciona-se à sensibilização do ser humano sobre algo, no caso, as consequências de um atentado terrorista. A ação de sensibilizar acontece dentro do próprio ser, isto é, em seu íntimo, sendo, portanto, algo que se distancia de sua superficialidade (da superficialidade do contêiner) e vai em direção a sua essência (ao fundo do contêiner). Essa ideia de sensibilização é também observada em expressões metonímicas como "tocar fundo no coração/ na alma / na consciência".

(3) No entanto, pensamos que as consequências deste atentado têm de tocar mais fundo e ir além do momento conjuntural. (TF)

No CRP, "tocar fundo" tem 491 ocorrências e atinge os valores mínimos em dois dos três testes estatísticos adotados (escore T: 19,30; e LogDice: 3,78). Somente o resultado da informação mútua $(2,95)$ não atinge o valor mínimo adotado de 3 . Assim sendo, ele foi identificado como um fraseologismo metafórico e incluído como um dos casos a serem considerados em nossa análise.

Ao traduzirem o Exemplo 3, os participantes da pesquisa sugeriram: go further, play deeper, go deeper e touch deeper. Os códigos na coluna "Participantes" referem-se aos estudantes que optaram pela mesma tradução, a qual foi escolhida aleatoriamente para exemplificar uma mesma formulação em língua inglesa para o fraseologismo em português. Organizamos a ordem de apresentação dos excertos partindo de soluções tradutórias não ou pouco convencionais para as mais convencionais. 


\section{REVISTA DA ABRALIN}

\begin{tabular}{|c|c|}
\hline Tradução & Participantes \\
\hline ... consequences of this attack need to go further and beyond the situational moment. & TA2 \\
\hline $\begin{array}{l}\text {... the consequences of this attack have to play deeper and go beyond the conjunctural } \\
\text { moment. }\end{array}$ & TA4, TA15 \\
\hline onsequences of this attack must go d & $\begin{array}{l}\text { TA3, TA8, TA17, } \\
\text { TA18, TA19 }\end{array}$ \\
\hline $\begin{array}{l}\text {... consequences of this terrorist attack must touch deeper and go beyond this conjuctural } \\
\text { moment. }\end{array}$ & $\begin{array}{l}\text { TA1, TA7, TA14, } \\
\text { TA16, TA20 }\end{array}$ \\
\hline
\end{tabular}

QUADRO 1 - Traduções do fraseologismo "tocar fundo" para a língua inglesa Fonte: os autores

O fraseologismo go further é estatisticamente relevante (54.987 ocorrências; escore T: 214,53; informação mútua: 3,55; LogDice: 6,26). Ele tem condição de mapeamento diferente, isto é, relaciona-se ao domínio fonte de direção/movimento e não ao do contêiner, base da metáfora conceitual de "tocar fundo", o que não seria um problema. Contudo, observamos no CRI que a tradução sugerida é semanticamente incompativel com o contexto do fraseologismo do texto fonte, não tendo relação com a noção de sensibilização (cf. Exemplo 4), razão pela qual o consideramos FraMNConv.

(4) In a new video, former Labor Secretary Robert Reich calls on President Obama to go further and ban all political spending by corporations that get most of their business from government contracts. (CRI)

A tradução play deeper é compreendida como uma sequência lexical já que ela não atende ao critério estatístico estipulado (83 ocorrências; escore T: -12,55; informação mútua: 1,25; LogDice: 1,0). Além disso, a análise do CRI indica que essa sequência lexical é semanticamente incompatível com o fraseologismo do texto fonte, não fazendo referência à situação abordada nem de modo amplo (cf. Exemplo 5). Por esse motivo, ela é classificada como FraMNConv.

(5) Plus, they also have a well organised defence, and a deep lying midfielder in Mascherano that can play deeper when required. (CRI)

No corpus de referência em inglês (CRI), constatamos que go deeper (18.526 ocorrências; escore T: 132,58; informação mútua: 5,27; LogDice: 4,97), vincula-se à metáfora do contêiner em grande parte das ocorrências (go deeper into something - Exemplo 6). No entanto, em se tratando da metáfora conceitual o CORPO É UM CONTÊINER, localizamos um caso em apenas uma ocorrência (Exemplo 7).

(6) [...] and appeal not only to Vaishnavas but also the thousands of yoga practioners in the growing yoga world, who want to go deeper into the tradition and pass it on to their children too. (CRI)

(7) Mahatma Gandhi, we took a day in silence and also a gentle fasting (only having fruit for lunch). A time to reflect, to go deeper into ourselves and discover what is there. (CRI) 


\section{REVISTA DA ABRALIN}

Apesar de a maioria das ocorrências de go deeper no CRI não estarem relacionadas à noção de sensibilização, de um modo mais amplo, há uma aproximação semântico-cognitiva, se considerarmos a manutenção do domínio do contêiner em grande parte das linhas de concordância. Por ser estatisticamente forte e por não haver uma incompatibilidade semântica com o fraseologismo do texto fonte, consideramos go deeper como FraMConv.

Ao analisar as linhas de concordância de touch deeper no CRI, constatamos que há predomínio da metáfora com ocorrências compatíveis com o fraseologismo do TF. O fraseologismo coocorre inclusive com heart, life, souls, inner feelings, emotions, referindo-se, metonimicamente e, em uma aproximação com o fraseologismo do texto fonte, ao próprio ser. Contudo, touch deeper não é uma associação estatisticamente significativa (160 ocorrências; escore T: -0,40; informação mútua: -0,05; LogDice: 0,58). Por isso, seguindo os critérios estabelecidos, classificamos a sequência como um FraMPConv.

Verificamos, porém, que os aprendizes parecem ter feito uma escolha não muito adequada ao contexto (ao menos em relação à frequência de uso) para traduzir "tocar fundo". Quando o verbo touch é empregado com o advérbio deeply (cf. Exemplos 8 e 9), tem-se um fraseologismo metafórico convencional, tanto do ponto de vista estatístico (3.182 ocorrências; escore T: 61,50; informação mútua: 6,42; LogDice: 5,97$)$ quanto da metaforicidade.

(8) the Liturgy in particular must shine out with all its power as a communicative feature to deeply touch the human conscience, the heart and intellect. (CRI)

(9) It was while he was there that he had the opportunity to meet Pope Francis, which deeply touched him. (CRI)

Tais excertos, a partir de evidências linguísticas como human conscience (Exemplo 8) e do pronome him (Exemplo 9), reforçam que a metáfora conceitual subjacente à touch deeply é O CORPO É UM CONTÊINER, que compartilha de condição de mapeamento similar em relação ao fraseologismo "tocar fundo" em português.

\subsection{MEIOS SÃO CAMINHOS PARA UM PROPÓSITO}

Esta subseção enfoca fraseologismos que se relacionam à metáfora conceitual MEIOS SÃO CAMINHOS PARA UM PROPÓSITO (KÖVECSES, 2010), tal como "dar passos". No TF, a sequência "dar passos" é empregada em referência às ações de legisladores para evitar a demissão de um secretário.

(10) A desconfiança passou a orientar a ação dos legisladores governistas, que aprovaram sanções à Rússia contra a vontade da Casa Branca e deram passos para impedir que o presidente demita seu secretário de Justiça. (TF) 


\section{REVISTA DA ABRALIN}

(11) The State must take measures that actually force the SGP to grant the right to women to stand for election. (CRI)

Também é classificada como FraMConv a sequência act towards. O aprendiz, nesse caso, fez uma escolha menos óbvia se olharmos para a realização linguística já que não emprega a tradução literal para "dar" ou para "passos". Entretanto, act towards é uma combinação estatisticamente relevante (1.751 ocorrências; escore T: 28,10; informação mútua: 1,61; LogDice: 3,18) e que também se vincula à metáfora conceitual MEIOS SÃO CAMINHOS PARA UM PROPÓSITO, principalmente por força da preposição towards, que indica a direção a se tomar.

Por fim, a tradução take steps também atende aos critérios estatísticos estabelecidos (74.640 ocorrências; escore T: 254,41; informação mútua: 3,86; LogDice: 6,51), e, em sua grande maioria, os exemplos identificados no corpus de referência em inglês (CRI) são empregados em contextos metafóricos similares ao do texto fonte (cf. Exemplo 12). Trata-se, portanto, de um caso de FraMConv.

(12) We ask that the United States earnestly takes steps to resolve in a timely way the political issues around the debt ceiling. (CRI)

A metáfora conceitual MEIOS SÃO CAMINHOS PARA UM PROPÓSITO também contempla outros fraseologismos metafóricos nos textos fonte como "caminho novo" (2.144 ocorrências; escore T: 94,36; informação mútua: 4,91; LogDice: 6,73), "ponto de partida" (35.578 ocorrências; escore T: 187,61; informação mútua: 7,55; LogDice: 8,83) e "encontrar um caminho" (9.523 ocorrências; escore T: 27,12; informação mútua: 1,27; LogDice: 3,29).

(13) O presidente da França, Emmanuel Macron, quer impulsionar um "caminho radicalmente novo" em seu país. (TF)

(14) Quanto às escolas e demais grupos sociais organizados, o desafio é ainda maior. O ponto de partida [para enfrentar o bullying e a violência] é deixar claro para as pessoas que todos são bem-vindos, mas nem tudo que eles fazem é aceitável. (TF)

(15) Por exemplo a Tunísia, que penosamente tenta encontrar um caminho para a estabilidade, que integra tanto muçulmanos ortodoxos moderados quanto forças seculares. $(\mathrm{TF})$

Os aprendizes não tiveram dificuldades em traduzir esses exemplos e recorreram a fraseologismos metafóricos convencionais em língua inglesa em todos os casos. Para "caminho novo", as traduções foram new path (5.182 ocorrências; escore T: 59,98; informação mútua: 2,58; LogDice: 3,87) e new way (79.670 ocorrências; escore T: 253,60; informação mútua: 3,30; LogDice: 6,71).

(16) France's president, Emmanuel Macron, wants to impel a 'radically new path' in his country... (CEI) 


\section{REVISTA DA ABRALIN}

(17) The President of France, Emmanuel Macron, wants to impel a "radically new way" in the country... (CEI)

(18) Some countries of the Middle East and North Africa region are once again lighting up a new path. (CRI)

(19) LBJ offers a fascinating new history of the political upheavals of the 1960s and a new way to understand the last great burst of liberalism in America. (CRI)

Para "ponto de partida", 13 aprendizes sugeriram starting point (139.080 ocorrências; escore T: 371,45; informação mútua: 7,97; LogDice: 9,15) e um sugeriu start point (4.584 ocorrências; escore T: 47,34; informação mútua: 1,73; LogDice: 3,93). Como indicado, ambas as opções tradutórias atingiram os resultados mínimos em pelo menos dois testes estatísticos (starting point apresentou valores acima do mínimo para todos os três testes). No caso de starting point (cf. Exemplo 20), a prevalência de metáforas é bem maior que em start point, em que, identificamos, um equilíbrio entre ocorrências metafóricas (cf. Exemplo 21) e sentidos mais básicos/concretos (cf. Exemplo 22).

(20) Bearing in mind the Golden Rule, the Universal Declaration of Human Rights provides the ideal starting point from which to consider some of the main obligations between persons (CRI).

(21) But I think, or at least I would like to think, that is at least a good start point. (CRI)

(22) After a short drive along winding roads with huge drops to one side they arrived at the start point ready to climb Pic Du Canigou. (CRI)

Já, para "encontrar o caminho", 13 aprendizes optaram por find a way (2.714 ocorrências; escore T: 49,99; informação mútua: 4,63; LogDice: 2,50). No CRI, há predomínio de sentidos metafóricos nas linhas de concordância analisadas como indicado abaixo.

(23) Tunisia for example, that painfully tries to find a way towards stability, which integrates both moderate orthodox Muslims and secular forces. (CRI)

É interessante observar que, nos casos de "caminho novo", "ponto de partida" e "encontrar o caminho", as traduções foram todas feitas por fraseologismos metafóricos convencionais sem grandes dificuldades, o que pode ter relação com o fato de serem traduções diretas, as quais são combinações fortes na língua alvo e que compartilham de condições de mapeamento similares em português e em inglês. 


\section{REVISTA DA ABRALIN}

\subsection{DESISTIRÉ ABANDONAR O BARCO}

No tocante à metáfora conceitual DESISTIR É ABANDONAR O BARCO, analisamos o fraseologismo metafórico "abandonar o barco" (1.348 ocorrências; escore T: 35,52; informação mútua: 7,59; LogDice: 6,81). O Exemplo 24 diz respeito ao fato de o político Michel Temer ter desistido de apoiar a então presidenta Dilma Rousseff.

(24) Discreto organizador nos bastidores, o presidente soube abandonar o barco de Dilma Rousseff a tempo, reclamando de ser um "vice-presidente decorativo". (TF)

O fraseologismo foi traduzido por 17 aprendizes como indicado no Quadro 3.

\begin{tabular}{|l|l|}
\hline \multicolumn{1}{|c|}{ Tradução } & Participantes \\
\hline $\begin{array}{l}\text { Discreet backstage organizer, the president knew the best moment to abandon Dilma Rousseff, } \\
\text { claiming to be an "ornamental vice president". }\end{array}$ & TA6 \\
\hline $\begin{array}{l}\text { A discreet organizer in backstage, the president knew how to abandon Dilma Rousseff's part- } \\
\text { nership right on time, complaining of being a "decorative vice-president". }\end{array}$ & TA20 \\
\hline $\begin{array}{l}\text { Discreet organizer behind the scenes, the president knew the moment to leave Dilma Rousseff's } \\
\text { government in time, complaining about being a "decorative vice president". }\end{array}$ & TA19 \\
\hline $\begin{array}{l}\text { A discreet manager in the backstage, the president knew how to leave Dilma Rousseff's ship in } \\
\text { time, claiming to be a 'decorative vice-president'. }\end{array}$ & TA1, TA7, TA15 \\
\hline $\begin{array}{l}\text { Discreet organizer backstage, the President knew how to abandon Dilma Rousseff's ship in } \\
\text { time, claiming to be a "decorative vice-president". }\end{array}$ & TA2, TA8 \\
\hline $\begin{array}{l}\text { A discreet organizer behind the scenes, the president knew how to abandon Dilma Rousseff's } \\
\text { boat in time, complaining about being a "decorative vice president." }\end{array}$ & $\begin{array}{l}\text { TA5, TA10, } \\
\text { TA14, TA16, }\end{array}$ \\
\hline $\begin{array}{l}\text { Discreet organizer in the backstages, the President knew how to jump ship of Dilma Rousseff } \\
\text { in time, complaining of being a "decorative vice-President." }\end{array}$ & $\begin{array}{l}\text { TA3, TA4, } \\
\text { TA12, TA17 }\end{array}$ \\
\hline
\end{tabular}

Três aprendizes não empregaram um fraseologismo metafórico, optando por uma tradução literal: abandon Dilma Rousseff, abandon Dilma Rousseff's partnership e leave Dilma Rousseff's government. Dada a inexistência da imagem metafórica, haveria, nesses casos, uma perda do sentido figurado, mas não haveria uma incompatibilidade semântica, já que a ideia de abandono da presidenta se faz presente.

Alguns aprendizes empregaram leave ... ship (1.165 ocorrências, escore T: 26,62; informação mútua: 2,18; LogDice: 2,29); abandon ... ship (1.224 ocorrências, escore T: 34,53; informação mútua: 6,25; LogDice: 5,18) e abandon ... boat, (293 ocorrências, escore T: 15,70; informação mútua: 3,60; LogDice: 2,74). Dos três casos, somente leave ... ship não atende aos critérios estatísticos. Além disso, nota-se que há o predomínio do sentido básico nos três casos no CRI (cf. Exemplos 25-27). Por esses motivos, eles são classificados como FraMPConv.

(25) The captain and 14 of his crew have been arrested for being the first to leave the ship without helping all passengers to safety. (CRI) 


\section{REVISTA DA ABRALIN}

(26) Copt Schettino is charged with multiple manslaughter and with abandoning the ship before the evacuation of 4,200 passengers and crew was complete. (CRI)

(27) It was at this point that the kidnappers abandoned their boat and escaped into the bush, and when the Navy people came, I cried out to them that I was the one held hostage. (CRI)

O sentido metafórico da expressão, com condição de mapeamento similar, está presente em jump ship (2.314 ocorrências; escore T: 47,51; informação mútua: 6,34; LogDice: 5,71). Trata-se de um fraseologismo com valores estatísticos acima do limiar, sendo seus contextos predominantemente metafóricos no CRI (cf. Exemplo 28). É, assim, um FraMConv.

(28) Atiku said his decision to jump ship was because the ruling Peoples Democratic Party (PDP) has become irredeemable. (CRI)

A diferença em relação a "abandonar o barco" está na realização linguística, expressa por meio do verbo jump.

\subsection{TERRORISMO É FENÔMENO DA NATUREZA}

O fraseologismo metafórico "onda de atentados" (90 ocorrências; escore T: 13,71; informação mútua: 7,63; LogDice: 4,47) exemplifica a metáfora conceitual TERRORISMO É FENÔMENO DA NATUREZA. A força destruidora de um atentado terrorista assemelha-se à devastação provocada por uma onda, que se movimenta e invade regiões, como no Exemplo 29.

(29) às vésperas do primeiro ano do "califado" do EI, onda de atentados varre mundo árabe e atinge também a Europa. (TF)

A tradução desse fraseologismo metafórico foi convergente entre os participantes (cf. Quadro 4). Somente duas opções foram sugeridas, sendo que uma delas só foi proposta por um único aprendiz.

\begin{tabular}{|l|l|}
\hline \multicolumn{1}{|c|}{ Tradução } & Participantes \\
\hline $\begin{array}{l}\text { On the eve of the first year of the "caliphate" of IS, a wave of attempts sweeps through the } \\
\text { Arabic world and also hits Europe. }\end{array}$ & TA7 \\
\hline $\begin{array}{l}\text { In the eve of the first "caliphate" year of the Islamic State, a wave of attacks sweeps the Arabic } \\
\text { world and also reaches Europe. }\end{array}$ & TA3, TA2, \\
& TA8, TA14, \\
& TA15, TA16, \\
TA17, TA18, \\
\hline
\end{tabular}

QUADRO 4 - Traduções do fraseologismo "onda de atentados" para a língua inglesa Fonte: os autores 


\section{REVISTA DA ABRALIN}

O emprego de wave com attempts não foi identificado na lista de coocorrência no CRI, e, por esse motivo, os testes estatísticos não foram realizados. Apesar de a tradução proposta ter uma aura metafórica, devido ao emprego de wave, a sequência wave of attempts não parece fazer sentido no contexto em questão. Devido a essa incompatibilidade semântica com o fraseologismo do texto fonte, a tradução, nesse caso, foi considerada um FraMNConv.

Já wave of attacks tem relevância estatística (2.148 ocorrências; escore T: 43,41; informação mútua: 3,98; LogDice: 4,29), é majoritariamente metafórica nas linhas de concordância e apresenta condição de mapeamento similar a "onda de atentados" (cf. Exemplo 29). Essa sequência lexical em inglês é considerada FraMConv.

(30) On Monday, Israeli jets carried out three waves of attacks on Gaza, raising security concerns over whether the Emir of Qatar should actually go to the enclave. (CRI)

Percebe-se, pelo Quadro 4, que, à exceção de um único aprendiz, a maioria dos aprendizes optaram pela tradução direta, mostrando, neste caso, ser uma estratégia de tradução que os favoreceu.

\section{Considerações finais}

Este artigo teve por propósito apresentar a contribuição teórico-metodológica da LC na condução de um trabalho interdisciplinar que contempla outras duas áreas do conhecimento - os Estudos da Metáfora e da Tradução. Na presente pesquisa sobre a tradução de fraseologismos metafóricos da língua portuguesa para a língua inglesa por aprendizes universitários, empregamos alguns dos corpora e das funcionalidades disponibilizadas na ferramenta Sketch Engine.

Nos dados examinados, os aprendizes apresentaram uma tendência à manutenção do mapeamento metafórico da língua fonte na língua alvo sempre que possível. Isso não significa, contudo, que eles necessariamente lançam mão de escolhas metafóricas mais convencionais. Em "tocar fundo", por exemplo, há condição de mapeamento similar na tradução (touch deeper), mas se trata de uma combinação que tem força associativa baixa. Um fraseologismo metafórico convencional correspondente em inglês é touch deeply, estatisticamente forte e metafórico, porém, não empregado por nenhum aprendiz, talvez por desconhecimento sintático da língua inglesa. Em fraseologismos como "caminho novo", "ponto de partida" e "encontrar o caminho", os aprendizes parecem não ter enfrentado dificuldades tradutórias: todos aqueles que os traduziram sugeriram fraseologismos metafóricos convencionais com condições de mapeamento similar.

Além da tentativa de manutenção de condições de mapeamento similares, é possível observar que alguns aprendizes também optam pela manutenção de escolhas lexicais prima facie (e.g. abandon the boat para "abandonar o barco"). Tais escolhas se revelam fraseologismos metafóricos pouco 


\section{REVISTA DA ABRALIN}

convencionais quando se analisa o contexto metafórico em questão, uma vez que predominam sentidos mais básicos nas linhas de concordância no corpus de referência em inglês.

As análises também revelaram estratégias de evasão por parte dos aprendizes. Em alguns casos, eles optam pela omissão do fraseologismo metafórico quando da tradução para a língua inglesa ou fazem uma interpretação literal da metáfora do texto fonte. Não podemos afirmar o motivo pelo qual os aprendizes optam por essa estratégia: ela pode ser o resultado de uma escolha consciente ou do desconhecimento de uma possível alternativa tradutória. Não é possível responder a essa questão com os dados da presente pesquisa, tendo em vista que ela é calcada em uma abordagem textual. Em outras palavras, nosso foco de análise recai exclusivamente na tradução realizada pelos aprendizes como produto final. Para compreender o motivo pelo qual os participantes optaram por tais traduções, sugerimos um encaminhamento de pesquisa no qual seja adotado um enfoque processual da atividade tradutória. Para tanto, pode-se empregar protocolos verbais concomitantemente à realização da tradução ou pode-se realizar uma entrevista retrospectiva. Em ambos os casos, o objetivo é solicitar que o participante explique as suas decisões durante ou após o processo tradutório.

A análise aqui apresentada não tem um caráter exaustivo, mas ilustrativo. O método aqui proposto representa uma possibilidade concreta para a análise contrastiva de fraseologismos metafóricos. Dentre as inúmeras vantagens desse método, destacamos:

a) a análise empírica dos fraseologismos metafóricos calcada na investigação de corpora;

b) a inclusão de todas as sequências lexicais, sem a preocupação com a sua classificação em, por exemplo, expressões idiomáticas ou pacotes lexicais;

c) o emprego de corpora de referência comparáveis nas duas línguas analisadas (português e inglês), de forma a investigar a existência ou não de padrões lexicais e metafóricos nas sequências identificadas nos textos fonte e nas traduções sugeridas pelos aprendizes;

d) a análise em duas etapas, focando em fraseologismos e em usos metafóricos separadamente;

e) a definição de pontos de corte estatísticos para a identificação de fraseologismos a serem incluídos na análise, permitindo assim a replicação do estudo de forma mais fácil do que se a identificação fosse realizada com base na intuição do pesquisador;

f) o emprego de um critério menos subjetivo para a decisão a respeito do potencial metafórico de uma sequência lexical com base em uma análise de 100 linhas de concordância aleatoriamente selecionadas nos corpora de referência;

g) a adoção de uma taxonomia tripartite para a classificação dos dados da pesquisa, diferenciando claramente o que é típico e metafórico de outros usos. 


\section{REVISTA DA ABRALIN}

Em suma, o artigo mostra os "passos que podem ser dados" em direção a um "caminho novo" na análise contrastiva de fraseologismos metafóricos em diferentes línguas, evitando que futuros pesquisadores "abandonem o barco" interdisciplinar que é possibilitado pela interface entre corpora, metáfora e tradução.

\section{Agradecimentos}

Agradecemos à CAPES pelo financiamento da pesquisa, no âmbito do programa Capes-PrInt, edital $n^{\circ}$ 41/2017 (código de financiamento 001), que possibilitou parte de sua condução na Universidade de East Anglia (UEA), Reino Unido. Agradecemos, igualmente, à Faculdade de Educação e Aprendizagem ao Longo da Vida (School of Education and Lifelong Learning), pela isenção das taxas escolares que também permitiram a realização da pesquisa na UEA.

\section{REFERÊNCIAS}

BAKER, M. Corpus linguistics and translation studies: implications and applications. In: BAKER, M. et al. (Eds.). Text and technology. Amsterdam: John Benjamins, 1993.

BAKER, M. Corpora in translation studies: an overview and some suggestions for future research. Target, v. 7, n. 2, p. 223-243, 1995.

BAKER, P. Using corpora in discourse analysis. London: Continuum, 2006.

BARBOSA, T. M. Estudo contrastivo das emoções em expressões idiomáticas corporais do italiano e do português brasileiro: uma vertente cognitivista. 197 f. Instituto de Biociências, Letras e Ciências Exatas, Universidade Estadual Paulista, São José do Rio Preto, 2014.

BERBER SARDINHA, T. Linguística de corpus. Barueri: Manole, 2004

BERBER SARDINHA, T. Análise de metáforas em corpora. Ilha do Desterro, n. 52, p. 167-199, 2007.

BERBER SARDINHA, T. Metáforas e linguística de corpus: metodologia de análise aplicada a um gênero de negócios. Revista Delta, São Paulo, v. 27, p. 1- 20, 2011. DOI: http://dx.doi.org/10.1590/S010244502011000100001. Acesso em: mar. 2017.

BIBER, D.; REPPEN, R. (Eds.). The Cambridge handbook of English corpus linguistics. Cambridge: Cambridge University Press, 2015.

BREZINA, V.; MCENERY, T.; WATTAM, S. Collocations in context: a new perspective on collocation networks. International Journal of Corpus Linguistics, v. 20, n. 2, p. 139-173, 2015. DOI:

https://doi.org/10.1075/ijcl.20.2.01bre Acesso em: out. 2019. 


\section{REVISTA DA ABRALIN}

BROWN, H. D. Principles of language learning and teaching. 5. ed. White Plains, NY: Pearson Longman, 2007.

CAMBRIDGE ENGLISH DICTIONARY. Cambridge University Press 2020. Disponível em:

https://dictionary.cambridge.org/.

CARNEADO MORÉ, Z. La fraseologia en los diccionarios cubanos. La Habana: Editorial de Ciencias Sociales, 1985.

CORPAS PASTOR, G. Manual de fraseología española. Madrid: Gredos, 1996.

DEIGNAN, A. A corpus-based study of some linguistic features of metaphor. 1997. $387 \mathrm{f}$. Tese (Doutorado) -

Faculdade de Artes, Universidade de Birmingham, Birmingham, 1997.

DEIGNAN, A. Metaphor and corpus linguistics. Amsterdam: John Benjamins, 2005.

DUTRA, D. P.; BERBER-SARDINHA, T. Pacotes lexicais em corpora de aprendizes. In: IBAÑOS, A. M. T.; MOTTIN, L. P.; SARMENTO, S.; BERBER SARDINHA, T. (Orgs.) Pesquisa e perspectivas em linguística de corpus. Campinas: Mercado de Letras, 2015, p. 57-80.

DURRANT, P.; SCHMITT, N. To what extent do native and non-native writers make use of collocations? IRAL, v. 47, p. 157-177, 2009. DOI: https://doi.org/10.1515/iral.2009.007. Acesso em: abr. 2019.

EVERT, S. The statistics of word cooccurrences: word pairs and collocations. 2005. $353 \mathrm{f}$. Tese (Doutorado) Institut für maschinelle Sprachverarbeitung, University of Stuttgart, 2005.

FINATTO, M. J. B.; REBECHI, R. R.; SARMENTO, S.; BOCORNY, A. E. P. (Orgs.) Linguística de corpus: Perspectivas Porto Alegre: Instituto de Letras, UFRGS, 2018.

FONSECA, H. da C. Fraseologismos zoônimos: elaboração de base de dados português francês. 2013. 187 f. Dissertação (Mestrado em Estudos Linguísticos) - Instituto de Biociências, Letras e Ciências Exatas, Universidade Estadual Paulista, São José do Rio Preto, 2013.

FRANKENBERG-GARCIA, A. Investigating the collocations available to EAP writers. Journal of English for Academic Purposes, v. 35, p. 93-104, 2018. DOI: https://doi.org/10.1016/j.jeap.2018.07.003. Acesso em: out 2019.

GRANGER, S.; PAQUOT, M. Disentangling the phraseological web. In: GRANGER, S.; PAQUOT, M.; MEUNIER, F. (Eds.). Phraseology: an interdisciplinary perspective. Amsterdam: John Benjamins, 2008. p. 27-50.

GRANGER, S.; LEFER, M-A. MUST: A collaborative corpus collection initiative for translation teaching and research. In: GRANGER, S., LEFER, M.-A.; PENHA-MARION, L. (Eds.), Book of Abstracts. Using Corpora in Contrastive and Translation Studies Conference (5th edition). CECL Papers 1. Louvain-la-Neuve: Centre for English Corpus Linguistics/Université catholique de Louvain, p. 72-73, 2018. Disponível em https://uclouvain.be/en/research-institutes/ilc/cecl/cecl-papers.html.Acesso em: set. 2020.

GRUPO PRAGGLEJAZ. MIP: A method for identifying metaphorically used words in discourse. Metaphor and symbol, v. 22, n. 1, p. 1-39, 2007.

HOUAISS, A. Dicionário eletrônico Houaiss da língua portuguesa: versão 3.0.1. Rio de Janeiro: Objetiva, 2009. 1 CDROM.

HUNSTON, S. Corpora in applied linguistics. Cambridge: Cambridge University Press, 2002.

HYLAND, K.; CHAU, M. H.; HANDFORD, M. (Eds.). Corpus applications in applied linguistics. London: Continuum, 2012 . 


\section{REVISTA DA ABRALIN}

KILGARRIFF, A. BAISA, V.; BUŠTA, V.; JAKUBÍČEK, M.; KOVÁŘ, V.; MICHELFEIT, J.; RYCHLÝ, P.; SUCHOMEL, V. The sketch engine: ten years on. Lexicography: Journal of ASIALEX, v. 1, n.1, p. 7-36, 2014. DOI: https://doi.org/10.1007/s40607-014-0009-9. Acesso em: maio 2017.

KÖVECSES, Z. Metaphor: a practical introduction. New York: Oxford University Press, 2010.

LAKOFF, G.; JOHNSON, M. Metaphors we live by. Chicago: The University Press of Chicago, 2003 [1980].

LAKOFF, G. Women, fire and dangerous things. Chicago: University of Chicago Press, 1987.

MACARO, E. Learning strategies in foreign and second language classrooms. London: Continuum, 2001.

MACMILLAN DICTIONARY. Macmillan Education Limited 2009-2020. Disponível em:

https://www.macmillandictionary.com/

MANDELBLIT, N. The cognitive view of metaphor and its implications for translation theory. Translation and Meaning, v. 3, p. 483-495, 1995.

MAURANEN, A. Strange strings in translated language: a study on corpora. In: OLOHAN, M. (Ed.). Intercultural faultlines. research models in translation studies: textual and cognitive aspects. Manchester: St. Jerome Publishing, 2000. p. $119-141$.

MAURANEN, A. Universal tendencies in translation. In: ANDERMAN, G.; ROGERS, M. (Eds.). Incorporating corpora: the linguist and the translator. Clevendon: Multilingual Matters, 2008. p. $32-48$.

MCENERY, T.; WILSON, A. Corpus linguistics: an introduction. Edinburgh: Edinburgh University Press, 2001. MCENERY, T.; HARDIE, A. Corpus linguistics: methods, theory and practice. New York: Cambridge University Press, 2012.

NESSELHAUF, N. Collocations in a learner corpus. Amsterdam: John Benjamins Publishing Company, 2005.

O'KEEFFE, A.; MCCARTHY, M. (Eds.). The Routledge handbook of corpus linguistics. London: Routledge, 2010.

ORTÍZ ALVAREZ, M. L. Expressões idiomáticas do português do Brasil e do Espanhol de Cuba: estudo contrastivo e implicações para o ensino de português como língua estrangeira. 2000. Tese de doutorado. IEL, UNICAMP, Campinas, 2000.

ROCHA, J. M. P. Fraseologia jurídico-comercial e proposta de um glossário de colocações especializadas trilíngue baseado em corpus. 2017. 292 f. Dissertação (Mestrado em Estudos Linguísticos) - Instituto de Biociências, Letras e Ciências Exatas, Universidade Estadual Paulista, São José do Rio Preto, 2017.

ROCHA, J. M. P.; ORENHA-OTTAIANO, A. Colocações especializadas na área do Direito Comercial Internacional e proposta de glossário trilíngue. In: FINATTO, M. J. B.; REBECHI, R. R.; SARMENTO, S.; BOCORNY, A. E. P. (Orgs.). Linguística de corpus: perspectivas. Porto Alegre: Instituto de Letras, UFRGS, 2018. p. 299 - 321.

ROCHA, J. M. P. Tradução de fraseologismos metafóricos do português para o inglês: um estudo de corpus de aprendizes brasileiros. Tese (Doutorado em Estudos Linguísticos - Instituto de Biociências, Letras e Ciências Exatas, Universidade Estadual Paulista, São José do Rio Preto. (Inédito)

RUIZ GURILLO, E. Aspectos de fraseología teórica española. Valencia: Universitat de València, 1997. 


\section{REVISTA DA ABRALIN}

SHEPHERD, T.; ZYNGIER, S.; VIANA, V. Feixes lexicais e visões de mundo: Um estudo sobre corpus. Matraga, v. 19, p. 125-140, 2006.

STEEN, G. Finding metaphor in grammar and usage: a methodological analysis of theory and research. Amsterdam: John Benjamin Pusblishing, 2007.

STUBBS, M. Words and phrases: Corpus-based studies of lexical semantics. Oxford: Routledge, 2001.

TAGNIN, S. E. O. O jeito que a gente diz: Expressões convencionais e idiomáticas. São Paulo: Disal, 2013.

TRISTÁ PÉREZ, M. A. Fraseología y contexto. Habana: Editorial de Ciencias Sociales, 1988.

VALENÇA, E. M. A tradução de expressões idiomáticas de baixa dedutibilidade metafórica: contribuições aos estudos fraseológicos bilíngues. 2016. 191 f. Instituto de Biociências, Letras e Ciências Exatas, Universidade Estadual Paulista, São José do Rio Preto, 2016.

VEREZA, S. O lócus da metáfora: linguagem, pensamento e discurso. Cadernos de Letras da UFF, n. 41, p. 199-212, 2010.

VEREZA, S. "Metáfora é que nem...”: cognição e discurso na metáfora situada. Signo, v. 38, n. 65, p. 2-21, jul./ dez., 2013. DOI: http://dx.doi.org/10.17058/signo.v38i65.4543. Acesso em: nov. 2019.

VIANA, V. Linguistica de corpus: Conceitos, técnicas e análises. In: VIANA, V.; TAGNIN, S. E. O. (Eds.). Corpora no ensino de línguas estrangeiras. São Paulo: Hub Editorial, 2011. p. 25-95.

VIANA, V.; TAGNIN, S. E. O. (Eds.). Corpora na tradução. São Paulo: Hub Editorial, 2015.

VIANA, V.; ZYNGIER, S. EFL through the digital glass of corpus linguistics. In: MARRIOTT, R. C. V.; TORRES, P. L. (Eds.), Handbook of research on e-learning methodologies for language acquisition. Hershey: Information Science Reference, 2009. p. 219-236.

VIANA, V.; ZYNGIER, S.; BARNBROOK, G. (Eds.). Perspectives on Corpus Linguistics. Amsterdam and Philadelphia: John Benjamins, 2011.

WRAY, A. Formulaic language and the lexicon. Cambridge: Cambridge University Press, 2002.

ZULUAGA, A. Introducción al estudio de las expresiones fijas. Frankfurt: Peter D. Lang, 1980. 